\title{
Fasciotomy for Lateral Lower-leg Chronic Exertional Compartment Syndrome
}

Citation for published version (APA):

van Zantvoort, A. P. M., de Bruijn, J. A., Hundscheid, H. P. H., van der Cruijsen-Raaijmakers, M., Teijink, J. A. W., \& Scheltinga, M. R. (2018). Fasciotomy for Lateral Lower-leg Chronic Exertional Compartment Syndrome. International Journal of Sports Medicine, 39(14), 1081-1087. https://doi.org/10.1055/a-06409104

Document status and date:

Published: 01/12/2018

DOI:

10.1055/a-0640-9104

Document Version:

Publisher's PDF, also known as Version of record

Document license:

Taverne

Please check the document version of this publication:

- A submitted manuscript is the version of the article upon submission and before peer-review. There can be important differences between the submitted version and the official published version of record.

People interested in the research are advised to contact the author for the final version of the publication, or visit the DOI to the publisher's website.

- The final author version and the galley proof are versions of the publication after peer review.

- The final published version features the final layout of the paper including the volume, issue and page numbers.

Link to publication

\footnotetext{
General rights rights.

- You may freely distribute the URL identifying the publication in the public portal. please follow below link for the End User Agreement:

www.umlib.nl/taverne-license

Take down policy

If you believe that this document breaches copyright please contact us at:

repository@maastrichtuniversity.nl

providing details and we will investigate your claim.
}

Copyright and moral rights for the publications made accessible in the public portal are retained by the authors and/or other copyright owners and it is a condition of accessing publications that users recognise and abide by the legal requirements associated with these

- Users may download and print one copy of any publication from the public portal for the purpose of private study or research.

- You may not further distribute the material or use it for any profit-making activity or commercial gain

If the publication is distributed under the terms of Article $25 \mathrm{fa}$ of the Dutch Copyright Act, indicated by the "Taverne" license above, 


\title{
Fasciotomy for Lateral Lower-leg Chronic Exertional Compartment Syndrome
}

\author{
Authors \\ Aniek Philomena Maria van Zantvoort ${ }^{1}$, Johan Anthonius de Bruijn ${ }^{1}$, Henricus P. H. Hundscheid ${ }^{1}$, Marike van der \\ Cruijsen-Raaijmakers ${ }^{2}$, Joep A. W. Teijink ${ }^{3}$, Marc R. Scheltinga ${ }^{1}$
}

\author{
Affiliations \\ 1 Máxima Medical Center, Surgery, Veldhoven, Netherlands \\ 2 Máxima Medical Center, Sports Medicine, Veldhoven, \\ Netherlands \\ 3 Catharina Ziekenhuis, Surgery, Eindhoven, Netherlands
}

\author{
Key word \\ CECS, surgery, intracompartmental pressure measurement, \\ operation
}

accepted 29.05.2018

\author{
Bibliography \\ DOI https://doi.org/10.1055/a-0640-9104 \\ Published online: 12.11.2018 \\ Int J Sports Med 2018; 39: 1081-1087 \\ (c) Georg Thieme Verlag KG Stuttgart · New York \\ ISSN 0172-4622 \\ Correspondence \\ Miss Aniek Philomena Maria van Zantvoort, MD \\ Máxima Medical Center \\ Surgery, De Run 4600 \\ Veldhoven, $5500 \mathrm{MB}$ \\ Netherlands \\ Tel.: + 31/618/965 634, Fax: + 31/408/888 501 \\ aniekvanzantvoort@hotmail.com
}

\begin{abstract}
Exercise-induced lower leg pain may be caused by chronic exertional compartment syndrome (CECS). Anterior or deep posterior compartments are usually affected. Knowledge about CECS of the lateral compartment (lat-CECS) is limited and outcome after fasciotomy is unknown. The purpose of this study is to report on success rates of fasciotomy in patients with latCECS. Surgical success rates in patients with lat-CECS diagnosed with a dynamic intracompartmental pressure (ICP) measurement were studied using a questionnaire (success: excellent or good as judged by the patient; unsuccessful: moderate, fair or poor). We conducted ICP measurements in 247 patients for suspected lat-CECS, of whom 78 were positively diagnosed. Following exclusion ( $n=11), 30$ of the eligible 67 patients completed the questionnaire. Bilateral (70\%, $n=21 / 30)$ exertional pain $(97 \%, n=29)$ and a feeling of tightness $(93 \%, n=28)$ were the most frequently reported symptoms. Four years after fasciotomy, severity and frequency of symptoms had dropped significantly. Long-term surgical success was reported by $33 \%(n=10$; excellent $n=4$, good $n=6)$. Seventy-three percent $(n=22)$ had resumed sports activities (9 same level, 13 lower level). In conclusion, a fasciotomy for lat-CECS was successful in the long term in just one of three operated patients in this retrospective study.
\end{abstract}

\section{Introduction}

One of eight young patients with exercise-provoked leg pain suffers from a chronic exertional compartment syndrome (CECS) [18]. This syndrome is characterized by severe pain and tightness that is located in one or more lower leg compartments [27]. Patients with anterior and deep flexor CECS (ant-CECS, dp-CECS) are most frequently affected [2]. A recent study found that $12 \%$ of all CECS patients had involvement of the third compartment, termed the lateral lower leg compartment (lat-CECS) [24].

In general, results of an invasive, dynamic intracompartmental pressure measurement (ICP) are pivotal in the management of CECS. Pathologically elevated muscle compartment pressures according to predefined cut-off points are used for diagnosis and may support therapeutic measures [17]. If conservative therapy includ- ing rest and physical therapy fails, a fasciotomy is considered the therapy of choice [3]. Although results of surgery for ant-CECS and $\mathrm{dp}$-CECS are well documented, the surgical literature on lat-CECS is exceedingly scarce. Surgical success rates on a total of only 57 lat-CECS patients were identified from the literature ( $\triangleright$ Table 1 ) $[7,11-14,16,22,25]$. Interestingly, most surgical data were obtained from operations on patients with a combined ant-CECS/latCECS syndrome. Conversely, just one case series of small volume $(n=3)$ reported on operative results for isolated lat-CECS [13].

Our department of sports medicine is a referral centre for evaluation of CECS. Since 2001, demographics, baseline characteristics and ICP have been prospectively entered in a digital database. The aim of this study was to evaluate surgical outcomes in patients who were operated on for CECS involving the lateral compartment. 
- Table 1 Literature involving treatment for lat-CECS.

\begin{tabular}{|l|l|l|l|l|l|}
\hline Author, year & $\begin{array}{l}\text { Isolated lat-CECS / } \\
\text { combined lat-ant- } \\
\text { CECS (n/n patients) }\end{array}$ & $\begin{array}{l}\text { Lateral } \\
\text { compart- } \\
\text { ments (n) }\end{array}$ & Population & Treatment & Surgical outcome, (n) \\
\hline Martens et al., 1984 & Not reported (NR) & 3 & Athletes & $\begin{array}{l}\text { Conservative } \\
\text { and fasciotomy }\end{array}$ & NR \\
\hline Detmer et al., 1985 & NR & 29 & Athletes & Fasciotomy & NR \\
\hline Turnipseed et al., 1989 & NR & 245 & Predominantly athletes & $\begin{array}{l}\text { Fasciotomy } \\
\text { and fasciectomy }\end{array}$ & NR \\
\hline Verleisdonk et al., 1996 & NR & 2 & Predominantly military & Fasciotomy & NR \\
\hline Micheli et al., 1999 & $3 / 16$ & NR & Female athletes & Fasciotomy & 1 excellent, 2 fair \\
\hline Mouhsine et al., 2005 & $0 / 4$ & 7 & Athletes & $\begin{array}{l}\text { Minimal incision } \\
\text { fasciotomy }\end{array}$ & $\begin{array}{l}\text { "Good results in all 4 patients } \\
\text { at 2 years follow up" }\end{array}$ \\
\hline Packer et al., 2013 & $0 / 26$ & NR & NR & $\begin{array}{l}\text { Conservative } \\
\text { and fasciotomy }\end{array}$ & $\begin{array}{l}18 \text { successful (excellent/good), } \\
8 \text { not successful (fair/poor) }\end{array}$ \\
\hline Maffulli et al., 2016 & $0 / 8$ & 11 & Athletes & Fasciotomy & $\begin{array}{l}\text { All improved EQ-5D and } \\
\text { SF-36 scores }\end{array}$ \\
\hline Total & & 297 & & & \\
\hline
\end{tabular}

\section{Materials and Methods}

Since January 2001, characteristics including history, physical examination and ICP-measurements of patients referred to our facility for suspected CECS have been recorded in an electronic database. At the end of 2012, this database contained 1,384 patients. The first patient with a possible lat-CECS was evaluated in November 2001. For inclusion in the present study, patients were required to have at least one ICP above one of 3 threshold levels associated with CECS (Pedowitz criteria; $\geq 15 \mathrm{mmHg}$ at rest, $\geq 30 \mathrm{mmHg} 1 \mathrm{~min}$ after provocative exercise, or $\geq 20 \mathrm{mmHg} 5 \mathrm{~min}$ after provocative exercise) [17]. Details of our dynamic intracompartmental pressure measurement procedure were recently published [24]. All included patients had undergone a fasciotomy of the lateral compartment. A history of vascular claudication, significant lower leg trauma or surgery of the lower leg other than for CECS were considered exclusion criteria. The study was conducted according to the Declaration of Helsinki. The local ethics committee judged that evaluation of the study protocol was not required because this effort was considered a normal evaluation of the patient-related outcome (PRO) and an audit of the results. The hospital's medical ethical committee judged that the regulations specified in the Medical Research Involving Human Subjects Act (WMO) did not apply to the study protocol [8].

If history, physical examination and ICP were consistent with latCECS, the patient was informed of the diagnosis and management options. A portion of the patients decided on conservative therapy including rest, cooling, inlays or physical therapy. If the patient preferred an operation, he/she was offered the option to undergo the procedure in their referring facility or in our hospital. They were informed of the specifics of an operation and possible complications including hematoma, superficial peroneal nerve damage and wound infection.

If patients decided to undergo an operation in our hospital, they underwent an outpatient procedure under general or spinal anaesthesia. One hour before the operation, they received $2500 \mathrm{IU}$ of a low-molecular heparin subcutaneously. Outlines of the lateral com- partment including bony landmarks (fibular head, lateral malleolus) were identified by palpation and marked on the skin with a skin marker. The area of pain was determined by palpation. After sterile exposure, access to the fascia was obtained using two to three $4-5 \mathrm{~cm}$ longitudinal incisions. The length and number of incisions depended on the length of the leg and area of pain following preoperative palpation. The peroneal fascia was freed bluntly and opened in a longitudinal manner using a knife and scissors beyond the area of pain ( $\vee$ Fig. 1a). The superficial peroneal nerve that runs underneath ventral portions of this fascia was usually identified, thus preventing accidental damage. The skin incisions were closed intracutaneously ( $\triangleright$ Fig. 1b) followed by a one-day compressive bandage that was replaced by compressive stockings thereafter, $24 \mathrm{~h}$ a day for 2 weeks. A bilateral lat-CECS was surgically treated in a one-stage procedure. If a patient was diagnosed with a combined lateral and anterior CECS, an anterior tibialis muscle fasciotomy was performed simultaneously via a separate one-inch incision as reported [6]. If a patient suffered from a combined lat/dp-CECS, a fasciotomy of the lateral and deep flexor compartment was performed on one side. If successful, and if the patient suffered from a bilateral CECS, the contralateral side followed 6 weeks later. After one day, normal daily activities were allowed except for sports activities or jumping. If wound recovery was satisfactory at the 2-week postoperative outpatient check-up, patients were instructed to start bicycling and light jogging. Between week 4 and 8 postoperatively, the patient was allowed to intensify the exercise regimen to maximal levels.

In December 2013 and January 2014, efforts were made to contact all eligible patients by telephone. Once they were given study information and had provided verbal consent, they were asked to complete a set of questions that was sent later that day by mail or email. The questionnaire was developed to investigate the severity and frequency of 5 cardinal symptoms including pain, muscle weakness, cramps, a feeling of tightness and paraesthesia as experienced before surgery and at present using a verbal rating scale [10]. Terms such as "all the time", "most of the time", "half of the time", "sometimes" and "never" were used to quantify frequency whereas the 

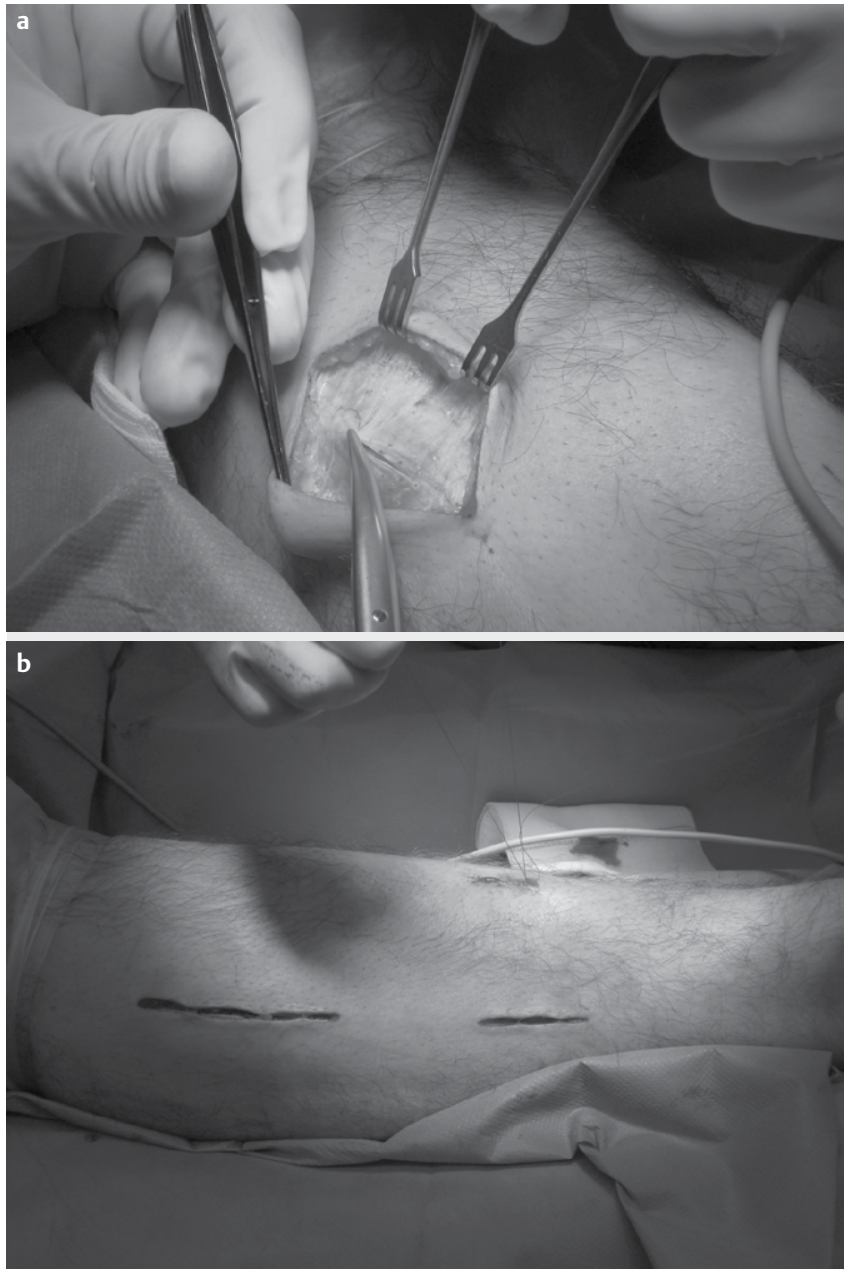

- Fig. 1 a The peroneal fascia is opened in a longitudinal manner using knife and scissors. b The skin incisions are closed intracutaneously.

terms "not at all”, "mild”, "moderate”, "severe" and "very severe" were used to grade severity. Patients also judged outcome at present using the adjectives "excellent", "good", "fair" or "poor". If patients had undergone a two-staged bilateral surgical procedure, they were instructed to report the outcome after completion of both operations. If patients had undergone an additional operation for ant-CECS or dp-CECS at a later time point, they were instructed to report on residual symptoms in the lateral aspect of the lower leg, being the area reflecting the lateral compartment. Nonresponders received two reminders by telephone, mail or email.

We calculated the area under the 4-point pressure curve in each patient having a complete set of 4 ICP measurements as suggested $(0.5 *$ resting pressure + pressure immediately after exercise + pressure $1 \mathrm{~min}$ after exercise $+0.5 *$ pressure 5 min after exercise) [27].

In order to approximate the overall effect of surgery, VRS scores of symptom frequency and symptom severity were converted into a numerical scale (symptom frequency: all the time $=5$ points, most of the time $=4$, half of the time $=3$, sometimes $=2$, never $=1$; symptom severity: very severe $=5$ points, severe $=4$, moderate $=3$, mild $=2$, not at all $=1$ ). For instance, if a patient experienced pain before the operation "most of the time" (4 points) as "severe" (4 points), his preoperative pain symptom score was $16(4 \times 4)$. Conversely, if he judged his pain after the operation as "sometimes" (2 points) "severe" ( 4 points), he received a postoperative score of 8 $(2 \times 4)$. The outcome after surgical treatment was defined as a success if patients reported the end result as excellent or good. In contrast, the outcome was unsuccessful if an average, fair or a poor result was achieved.

Statistical analysis was performed using SPSS statistics 22.0.0.0 (SPSS Inc. Chicago, IL, USA). Normality of distribution was determined using the Shapiro-Wilk test. If normal, data were expressed as mean \pm standard deviation (SD). If not, median and range were used. Differences between groups with respect to patient characteristics were analysed using Pearson's chi-squared test, or by Fisher's exact test if expected values in more than one cell of the cross table were below 5. A Mann-Whitney $U$ test was used to compare differences between two independent groups (either responders versus non-responders, or lat-CECS only versus combined lat-CECS) and to compare not normally distributed dependent variables that were either ordinal or continuous. An independent samples t-test was used to determine if there was a statistically significant improvement in symptom score after operation. A Kruskal-Wallis $\mathrm{H}$ test was used to determine if there was a relation between preoperative area under the ICP curve and postoperative outcome. Similarity of the shape of distribution was assessed by visual inspection of a boxplot. If distribution was similarly shaped, differences in medians were investigated. If distribution was not similarly shaped, differences in mean rank were investigated. A p $\leq 0.05$ was considered significant for all tests.

\section{Results}

In our facility, a total of 1,384 ICP measurements for suspected CECS were performed during the 12-year study period and 247 (18\%) were related to an ICP of the lateral lower leg compartment ( $\vee$ Fig. 2). Based on the Pedowitz criteria, 78 patients were diagnosed with lat-CECS ( $12 \%$ of all positive ICPs, 78/678). Two-thirds of this patient group $(64 \%, n=50)$ had a combination of a lat-CECS with a CECS of the anterior (ant-CECS; 42\%, 33/78), deep posterior (dp-CECS; $9 \%, 7 / 78)$ or both compartments (13\%, 10/78). In contrast, an isolated lat-CECS was detected in the remaining $36 \%$ $(n=28)$. After exclusion of 11 patients for reasons depicted in the flow diagram, 67 patients were eligible for the long-term followup via questionnaire. A total of 30 patients responded to this questionnaire ( $45 \%$ response rate). Questionnaires from the nonresponding patients were not available because their current whereabouts were unknown $(n=11)$ or repetitive requests were not acknowledged for unknown reasons $(n=26)$.

Sex distribution among patients undergoing a fasciotomy for lat-CECS $(n=30)$ was almost equal (53\% female, > Table 2 ). The median age at the time of diagnosis was 25 years (range 17-65), and follow-up was conducted at 4 years (median, range 1-11 years). Ten patients had an isolated lat-CECS. If lat-CECS patients suffered from a combined CECS $(n=20)$, the anterior compartment was frequently involved $(90 \%, 18 / 20)$. The combination dp-CECS with lat CECS was determined in just 4 patients (20\%). 


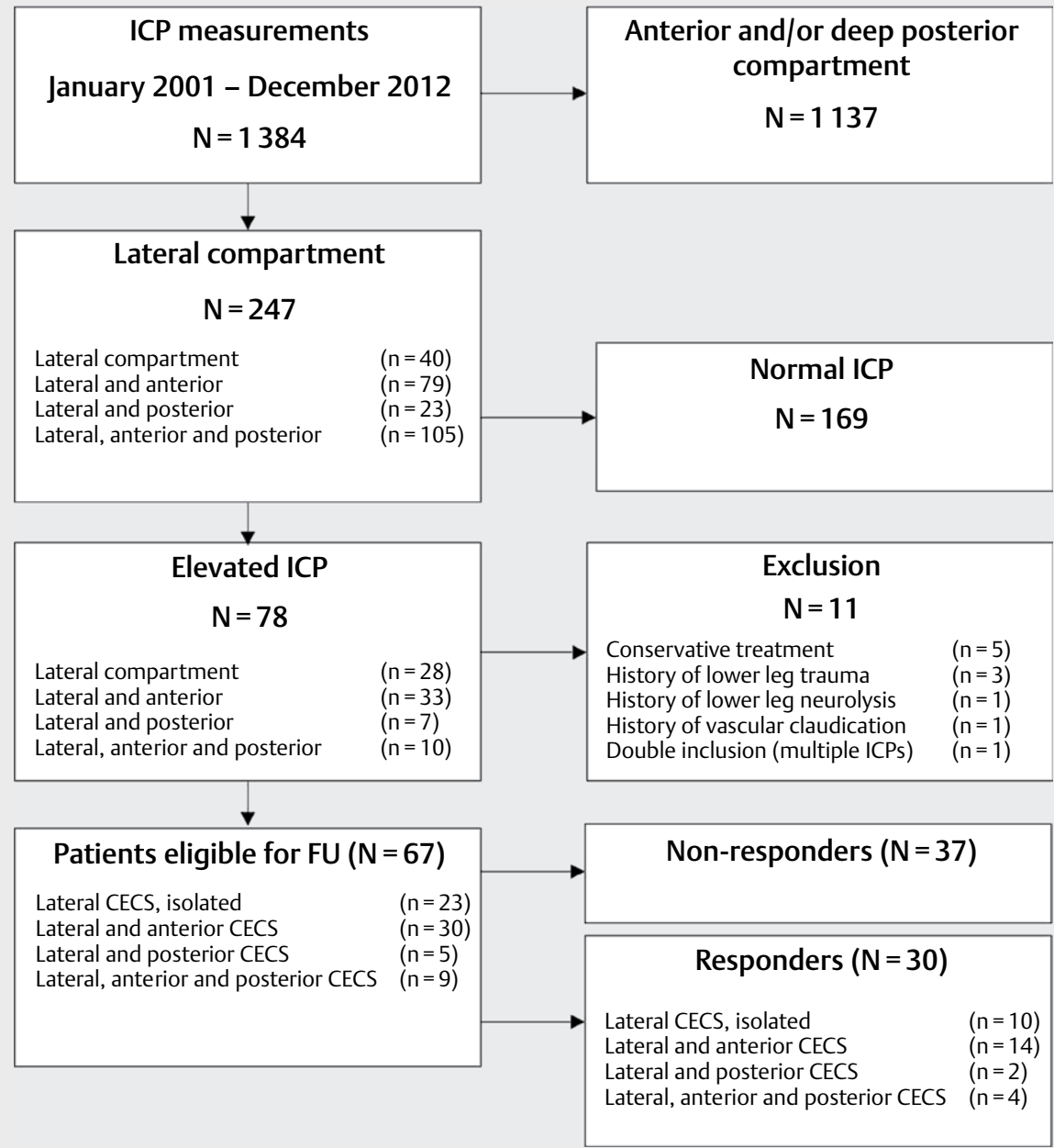

- Fig. 2 Flow chart of patients undergoing an intracompartmental pressure measurement (ICP) for suspected chronic exertional compartment syndrome (CECS) of the lateral lower-leg compartment.

The majority of the 30 lat-CECS patients reported bilateral symptoms ( $80 \%, 24 / 30)$. Two frequently reported symptoms were exertional pain $(97 \%, 29 / 30)$ and a feeling of tightness (93\%, $28 / 30)$. Patients also often experienced exertional muscle weakness (73\%, 22/30), paresthesias (70\%, 21/30) and/or cramps (70\%, $21 / 30)$. Except for one patient, all patients participated in sports activities. Prior to the operation, half ( $52 \%, 15 / 29,1$ missing value) of the patients had to completely terminate sports activities, $24 \%$ (7/29) pursued sport at a lower level, $10 \%$ (3/29) pursued sport with complaints and $14 \%$ had changed sports activities due to latCECS. No statistically significant differences in baseline characteristics were found between patients with an isolated lat-CECS or a combined compartment syndrome (age $U=77.0, z=1.015$, $p=0.328$; $B M I U=106.5, z=0.540, p=0.599$; rest $I C P U=137.5$, $z=1.652, p=0.100 ; I C P 1$ min after exertion $U=65, z=0.617$, $p=0.570 ;$ ICP $5 \min U=108.5, z=1.505, p=0.135)$.

Sixty percent $(18 / 30)$ received surgery in referring institutions and $40 \%(12 / 30)$ in our facility. Decrease in severity of symptoms after a median 4 years after surgery are depicted in $>$ Fig. 3. Pain, muscle weakness, cramps, feeling of tightness and paraesthesia all showed a significant decrease in mean pain score after fasciotomy (minimal $50 \%$ ). Long-term surgical success was attained in $33 \%$ of cases $(n=10$; excellent $n=4$, good $n=6 ; 30 \%$ of all lat-CECS patients (3/10), $35 \%$ of all combined CECS patients (7/20)). Conversely, the operation was deemed unsuccessful in $67 \%(n=20$; moderate $n=10$, fair $n=7$, poor $=3)$. A total of $73 \%(22 / 30)$ had resumed sports activities ( $9 / 30$ same level, 13/30 lower level). There was no significant difference in outcome between isolated lat-CECS or combined syndrome $(p=0.768, x(1)=0.087)$. Moreover, there was no significant difference in symptom relief between both groups $(p>0.05)$. Also, no statistically significant associations between outcome and sex $(p=0.442)$, uni- or bilaterality $(p=0.372)$, operating hospital (Máxima Medical Center, $42 \%$ successful, referral hospital $28 \%$ successful; $p=0.461$ ) or level of sports $(p=1.00)$ were present. Lastly, there was no statistically significant difference in preoperative "area under the ICP curve" between the five postoperative outcome groups at long-term follow-up ("excellent", "good", "moderate", "fair", "poor"; $\left.x^{2}(4)=3.918, p=0.417\right)$. Nevertheless, mean rank increased from "poor" (7.00), "fair" (9.50), “moderate" (11.31), "good" (12.25), to "excellent” (17.33). This 
- Table 2 Characteristics of questionnaire responders.

\begin{tabular}{|c|c|c|c|c|c|c|c|}
\hline $\mathbf{N}^{\circ}$ & $\begin{array}{l}\text { Affected } \\
\text { compartment }\end{array}$ & $\operatorname{Sex}(f / m)$ & $\begin{array}{l}\text { Age at } \\
\text { baseline (y) }\end{array}$ & BMI $\left(\mathrm{kg} / \mathrm{m}^{2}\right)$ & $\begin{array}{l}\text { Unilateral/ } \\
\text { Bilateral }\end{array}$ & $\begin{array}{l}\text { Level of sport } \\
\text { baseline }\end{array}$ & $\begin{array}{l}\text { Outcome } \\
\text { operation }\end{array}$ \\
\hline 1 & Lat & $\mathrm{F}$ & 49 & 21 & Unilateral & Social & Good \\
\hline 2 & Lat & $\mathrm{F}$ & 30 & 24 & Bilateral & Social & Poor \\
\hline 3 & Lat & $\mathrm{F}$ & 35 & 28 & Bilateral & Social & Average \\
\hline 4 & Lat & $\mathrm{M}$ & 28 & 21 & Bilateral & Local & Fair \\
\hline 5 & Lat & $\mathrm{F}$ & 23 & 31 & Bilateral & National & Good \\
\hline 6 & Lat & $\mathrm{M}$ & 25 & 25 & Bilateral & International & Average \\
\hline 7 & Lat & $\mathrm{F}$ & 65 & 32 & Bilateral & Social & Poor \\
\hline 8 & Lat & $\mathrm{F}$ & 22 & 30 & Bilateral & National & Average \\
\hline 9 & Lat & $M$ & 18 & 22 & Bilateral & International & Average \\
\hline 10 & Lat & $\mathrm{M}$ & 25 & 27 & Bilateral & Local & Excellent \\
\hline 11 & Dp-lat & $\mathrm{F}$ & 19 & 21 & Bilateral & National & Excellent \\
\hline 12 & Ant-dp-lat & $\mathrm{F}$ & 43 & 33 & Unilateral & Social & Average \\
\hline 13 & Ant-lat & $\mathrm{M}$ & 22 & 26 & Unilateral & Social & Excellent \\
\hline 14 & Ant-lat & $\mathrm{F}$ & 30 & 33 & Unilateral & Social & Average \\
\hline 15 & Ant-lat & $\mathrm{M}$ & 21 & 23 & Bilateral & Local & Average \\
\hline 16 & Ant-lat & $\mathrm{F}$ & 30 & 34 & Bilateral & Social & Fair \\
\hline 17 & Ant-dp-lat & $\mathrm{F}$ & 19 & 27 & Bilateral & Local & Fair \\
\hline 18 & Ant-lat & $\mathrm{F}$ & 23 & 23 & Bilateral & Social & Fair \\
\hline 19 & Ant-dp-lat & $\mathrm{F}$ & 40 & 38 & Bilateral & No & Poor \\
\hline 20 & Ant-lat & $\mathrm{F}$ & 17 & 25 & Bilateral & International & Fair \\
\hline 21 & Ant-lat & $\mathrm{F}$ & 23 & 26 & Bilateral & Local & Fair \\
\hline 22 & Ant-lat & $\mathrm{M}$ & 23 & 26 & Bilateral & National & Average \\
\hline 23 & Ant-lat & $M$ & 18 & 24 & Bilateral & Local & Good \\
\hline 24 & Ant-lat & $\mathrm{M}$ & 48 & 26 & Bilateral & Social & Average \\
\hline 25 & Ant-lat & $\mathrm{M}$ & 26 & 24 & Bilateral & Local & Average \\
\hline 26 & Ant-lat & $M$ & 36 & 35 & Bilateral & Local & Excellent \\
\hline 27 & Ant-lat & $M$ & 50 & 26 & Bilateral & Social & Good \\
\hline 28 & Dp-lat & $\mathrm{F}$ & 23 & 24 & Bilateral & Local & Good \\
\hline 29 & Ant-lat & $\mathrm{M}$ & 17 & 24 & Unilateral & National & Fair \\
\hline 30 & Ant-dp-lat & $M$ & 24 & 28 & Unilateral & National & Good \\
\hline
\end{tabular}

suggestive trend was not observed 3 months after surgery $\left(x^{2}(4)=1.066, p=0.900\right.$; "poor" (7.50), "fair" (11.92), "moderate" (12.10), "good" (12.50), "excellent" (10.33)).

\section{Discussion}

The aim of this study was to report on outcome in patients with lower leg lat-CECS undergoing a fasciotomy. The present report is the first large case series evaluating results of surgery for isolated lat-CECS or for a combined CECS including the lateral lower leg compartment. Four years after surgery, the severity and frequency of CECS-specific symptoms such as pain and tightness had dropped by at least $50 \%$. However, just one third of the patients rated the outcome as excellent or good even though most patients (73\%) had resumed sports activities.

Chronic exertional compartment syndrome is most common in young healthy athletes with a predisposition in women $[5,7,19,20,26]$. Patients in our study population diagnosed with
lat-CECS were 25 years old (median, range 17-65). The vast majority participated in sports activities and suffered from bilateral ( $80 \%)$ exertional pain $(97 \%, 29 / 30)$ and a feeling of lower leg tightness $(93 \%, 28 / 30)$. Sex distribution was almost equal ( $53 \%$ female). A striking $60 \%$ of all patients with lat-CECS also had an ant-CECS. Therefore each patient with exertional complaints of the anterolateral lower leg may suffer from a lat-CECS justifying a low threshold for ICP testing.

The Pedowitz criteria are the gold standard for diagnosing CECS. These generally used cut-off points were arbitrarily determined and a correlation with treatment outcome was never attained. Also, the Pedowitz criteria were never specified for the 3 different lower leg compartments [17]. Moreover, a recent study showed significant improvement of symptoms after fasciotomy in patients with normal ICP measurements who were treated surgically based on clinical examination only [15]. Therefore, the diagnostic value of the Pedowitz criteria is questionable. Overestimating the number of lat-CECS patients using this diagnostic tool may partially explain 
the present suboptimal outcome. We did not find a statistically significant correlation between preoperative ICP (area under the ICP curve) and surgical outcome for CECS in the lateral compartment. However, mean rank associated with degree of result increased substantially (poor, (7.0) to excellent (17.33)), possibly suggesting an improved outcome in patients with higher preoperative ICP. From January 2013 onwards we initiated a prospective study analysing surgical outcome in lat-CECS that may possibly allow us to determine whether ICP values predict surgical outcome.

There is some controversy regarding the exact frequency of the three types of lower leg CECS. Some studies suggest that the lateral compartment is second after the anterior compartment [5, 9, 23]. One study reported an up to $35 \%$ lat-CECS rate [2]. It is therefore somewhat strange why published results on surgery for this supposedly frequent type of lower leg CECS are scarce $[11,13,14,16]$. To date, the outcome of isolated CECS of the lateral compartment is reported in just 3 individuals, one with an excellent and 2 with a fair postoperative result [13]. In the largest population of combined latCECS patients ( $n=26$, all ant/lat-CECS), $73 \%$ were satisfied with the results of surgery [16]. Our population is the largest to date, consisting of 30 lat-CECS patients of whom 10 had an isolated lat-CECS. Even though all preoperative symptoms showed a significant decrease in mean pain score after fasciotomy, only a disappointing one of three patients undergoing fasciotomy rated their overall postoperative improvement 4 years later as excellent or good. In two patients with a failed operation (fair and poor, respectively), ICP measurements were again conducted demonstrating normality. Clinical reassessment did not provide an alternative diagnosis. The possibility of a condition other than CECS causing the symptoms such as neurovascular entrapments or medial tibial stress syndrome must always be considered, because the differential diagnosis of persisting exertional leg pain is rather extensive $[1,4]$.

The presence of untreated CECS is often very incapacitating for active individuals and negatively affects quality of life $[11,14]$. Up to $85 \%$ of CECS patients are unable to practice sports activities at the desired level before surgery $[11,21]$. The aim of the operation is to facilitate a return to a desired level of sports activity, but success is not always achieved. Just half of all operated CECS patients returned to sports practice in one study [14]. One other study of operated dp-CECS patients reported that only $38 \%$ returned to preinjury levels and $41 \%$ performed at lower levels [28]. The present study found that only $30 \%$ were able to resume sports activities at a similar level compared to their preoperative condition, whereas the remaining $70 \%$ performed at a lower level than previously. The profound effect of the presence of CECS on quality of life should not be underestimated in these active individuals. Therefore more prospective research is needed to improve surgical outcome and return to desired level of sports.

The retrospective nature of this study is associated with several limitations. The response rate was only $45 \%$. Moreover, there is a risk of both recall bias and information bias because patients were asked to recall severity and frequency of preoperative symptoms, sometimes even up to 10 years after the operation. Furthermore, documentation of baseline characteristics was occasionally incomplete and operations were done at various institutions. Therefore, a prospective study concisely monitoring patient characteristics and surgical results for lat-CECS was set up from January 2013 on- wards. Results of this prospective study will determine whether outcome of fasciotomy for lat-CECS is indeed inferior compared to other types of lower leg CECS.

\section{Conclusion}

Four years after surgery, just one in three patients who underwent a fasciotomy for lateral lower-leg chronic exertional compartment syndrome rated their outcome as excellent or good.

\section{Acknowledgements}

We want to thank our colleague A. Hoogeveen who provided his expertise and insight and conducted the intracompartmental pressure measurements for this manuscript.

\section{Conflict of interest}

The authors declare no conflict of interest.

\section{References}

[1] Apigian AK, Landry G]. Basic data underlying decision making in nonatherosclerotic causes of intermittent claudication. Ann Vasc Surg 2015; 29: 138-153

[2] Bong MR, Polatsch DB, Jazrawi LM, Rokito AS. Chronic exertional compartment syndrome: Diagnosis and management. Bull Hosp Jt Dis 2005; 62: 77-84

[3] Brennan FH Jr., Kane SF. Diagnosis, treatment options, and rehabilitation of chronic lower leg exertional compartment syndrome. Curr Sports Med Rep 2003; 2: 247-250

[4] Burrus MT, Werner BC, Starman JS, Gwathmey FW, Carson EW, Wilder RP, Diduch DR. Chronic leg pain in athletes. Am J Sports Med 2015; 43: 1538-1547

[5] Davis DE, Raikin S, Garras DN, Vitanzo P, Labrador H, Espandar R. Characteristics of patients with chronic exertional compartment syndrome. Foot Ankle Int 2013; 34: 1349-1354

[6] de Bruijn JA, van Zantvoort AP, Winkes MB, Raaymakers L, van der Cruijsen-Raaijmakers M, Hoogeveen AR, Scheltinga MR. Feasibility and safety of an operative tool for anterior chronic exertional compartment syndrome treatment. Foot Ankle Int 2015; 1475-1482

[7] Detmer DE, Sharpe K, Sufit RL, Girdley FM. Chronic compartment syndrome: Diagnosis, management, and outcomes. Am J Sports Med 1985; 13: $162-170$

[8] Harriss D], Macsween A, Atkinson G. Standards for ethics in sport and exercise science research: 2018 update. Int J Sports Med 2017; 38: $1126-1131$

[9] Howard JL, Mohtadi NG, Wiley JP. Evaluation of outcomes in patients following surgical treatment of chronic exertional compartment syndrome in the leg. Clin J Sport Med 2000; 10: 176-184

[10] Loos M], Houterman S, Scheltinga MR, Roumen RM. Evaluating postherniorrhaphy groin pain: Visual Analogue or Verbal Rating Scale? Hernia 2008; 12: 147-151

[11] Maffulli N, Loppini M, Spiezia F, D'Addona A, Maffulli GD. Single minimal incision fasciotomy for chronic exertional compartment syndrome of the lower leg. J Orthop Surg Res 2016; 11: 61 
[12] Martens MA, Backaert M, Vermaut G, Mulier JC. Chronic leg pain in athletes due to a recurrent compartment syndrome. Am J Sports Med 1984; 12: 148-151

[13] Micheli LJ, Solomon R, Solomon J, Plasschaert VF, Mitchell R. Surgical treatment for chronic lower-leg compartment syndrome in young female athletes. Am J Sports Med 1999; 27: 197-201

[14] Mouhsine E, Garofalo R, Moretti B, Gremion G, Akiki A. Two minimal incision fasciotomy for chronic exertional compartment syndrome of the lower leg. Knee Surg Sports Traumatol Arthrosc 2006; 14 : 193-197

[15] Orlin JR, Oen J, Andersen JR. Changes in leg pain after bilateral fasciotomy to treat chronic compartment syndrome: A case series study. J Orthop Surg Res 2013; 8: 193

[16] Packer JD, Day MS, Nguyen JT, Hobart SJ, Hannafin JA, Metzl JD. Functional outcomes and patient satisfaction after fasciotomy for chronic exertional compartment syndrome. Am J Sports Med 2013; 41: 430-436

[17] Pedowitz RA, Hargens AR, Mubarak S], Gershuni DH. Modified criteria for the objective diagnosis of chronic compartment syndrome of the leg. Am J Sports Med 1990; 18: 35-40

[18] Qvarfordt P, Christenson JT, Eklof B, Ohlin P, Saltin B. Intramuscular pressure, muscle blood flow, and skeletal muscle metabolism in chronic anterior tibial compartment syndrome. Clin Orthop Relat Res 1983; (179): 284-290

[19] Raikin SM, Rapuri VR, Vitanzo P. Bilateral simultaneous fasciotomy for chronic exertional compartment syndrome. Foot Ankle Int 2005; 26 : 1007-1011

[20] Reneman RS, Wieberdink ], Strackee ]. [Chronic anterior and chronic lateral compartment syndrome of the lower leg; a frequently not recognized syndrome?]. Ned Tijdschr Geneeskd 1971; 115: 543-551
[21] Slimmon D, Bennell K, Brukner P, Crossley K, Bell SN. Long-term outcome of fasciotomy with partial fasciectomy for chronic exertional compartment syndrome of the lower leg. Am J Sports Med 2002; 30: 581-588

[22] Turnipseed W, Detmer DE, Girdley F. Chronic compartment syndrome. An unusual cause for claudication. Ann Surg 1989; 210: 557-563

[23] Turnipseed WD. Diagnosis and management of chronic compartment syndrome. Surgery 2002; 132: 613-619

[24] van Zantvoort AP, de Bruijn JA, Winkes MB, Dielemans JP, van der Cruijsen-Raaijmakers M, Hoogeveen AR, Scheltinga MR. Isolated chronic exertional compartment syndrome of the lateral lower leg: a case series. Orthop J Sports Med 2015; 3: 2325967115617728

[25] Verleisdonk EJ, van den Helder C], Hoogendoorn HA, van der Werken $C$. [Good results of fasciotomy in chronic compartment syndrome of the lower leg]. Ned Tijdschr Geneeskd 1996; 140: 2513-2517

[26] Waterman BR, Liu J, Newcomb R, Schoenfeld AJ, Orr JD, Belmont PJ Jr. Risk factors for chronic exertional compartment syndrome in a physically active military population. Am J Sports Med 2013; 41: 2545-2549

[27] Winkes MB, Hoogeveen AR, Houterman S, Giesberts A, Wijn PF, Scheltinga MR. Compartment pressure curves predict surgical outcome in chronic deep posterior compartment syndrome. Am J Sports Med 2012; 40: 1899-1905

[28] Winkes MB, van Zantvoort AP, de Bruijn JA, Smeets S], van der Cruijsen-Raaijmakers M, Hoogeveen AR, Scheltinga MR. Fasciotomy for deep posterior compartment syndrome in the lower leg: A prospective study. Am J Sports Med 2016; 44: 1309-1316 